\title{
STABILITY OF MULTILAYER
}

SANDWICH PLATES

\author{
By \\ JULIUS PAN WONG \\ Diploma in Civil Engineering \\ Hong Kong Baptist College \\ Hong Kong \\ 1960 \\ Master of Science \\ Louisiana Polytechnic Institute \\ Ruston, Louisiana \\ 1962
}

Submitted to the Faculty of the Graduate School of the Oklahoma State University in partial fulfillment of the requirements for the degree of DOCTOR OF PHILOSOPHY May, 1966 


\section{STABILITY OF MULTILAYER} SANDWICH PLATES

Thesis Approved:

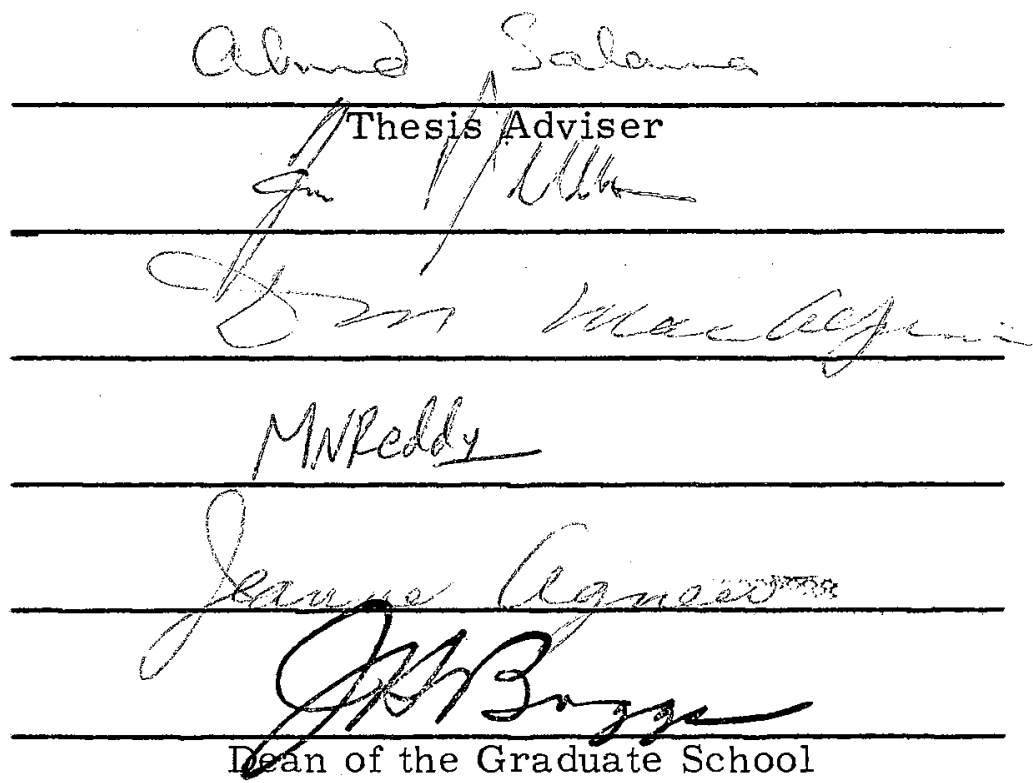




\section{ACKNOWLEDGEMENT}

The writer wishes to express his indebtness and sincere appreciation to the following individuals and organizations:

To Professor Jan J. Tuma and the School of Civil Engineering for awarding the Graduate Assistantship which made the graduate study possible;

To Professor Ahmed E. Salama, for his guidance and friendship throughout the preparation of this thesis;

To Professors Jan J. Tuma, David M. MacAlpine, Muppidi N. Reddy and Jeanne L. Agnew, members of the advisory committee and Dr. James W. Gillespie, Dr. Robert W. Little and Dr. Winifred O. Carter, former members of the advisory committee, for their helpful advice and encouragement throughout the writer's program;

To Dr. J. S. Kao and Professor Donald E. Boyd for their friendship and encouragement;

To the Faculty of the School of Civil Engineering and related departments for their valuable instruction;

To Dr. G. Avery Lee, Mr. Samuel Sanford and the Baptist Student Union at Louisiana Polytechnic Institute for awarding 
the scholarship which made the first two years of graduate study possible;

To Mr. Boen Dar Liaw for his valuable discussions;

To Messrs. Boen Dar Liaw, William H. Ying, Ergin Citipitioglu and Chung Yiu Wong, whose friendship has been much encouragement throughout the graduate work;

To his parents and sisters for their understanding and many sacrifices.

In addition, gratitude is due Mrs. Peggy Harrison, who typed the manuscript.

May, 1966

Stillwater, Oklahoma

Julius Pan Wong 


\section{TABLE OF CONTENTS}

Chapter

Page

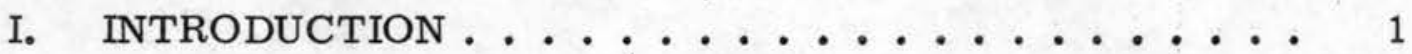

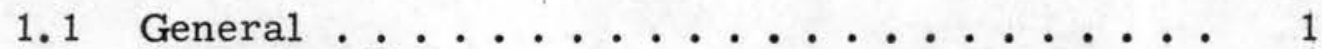

1.2 Historical Notes............ 2

II. GENERAL ANALYSIS . . . . . . . . . . . 4

2. 1 Statement of the Problem ........... 4

2.2 Stress Resultants and Equilibrium Equations ... 5

2. 3 Complementary Energy ........... 8

2. 4 Auxiliary Functional ........... 10

2.5 Compatibility Equations........... 12

2. 6 Lagrangian Multipliers .......... 15

2.7 Boundary Conditions .......... 17

2.8 General Analysis ............ 18

III. GOVERNING DIFFERENTIAL EQUATIONS . . . . 21

3. 1 Property Coefficients ........... 21

3. 2 Stress Resultants .............. 22

3. 3 Governing Differential Equations ......... 24

3. 4 Approximate Solution ......... 25

IV. SPECIALIZATION FOR EQUAL POISSON'S RATIOS . . . 27

4. 1 Poisson's Ratio ............. 27

4.2 Stress Resultants ............. 27

4. 3 Governing Differential Equations ........ 30

4. 4 Deflection Surface............ 32

4.5 Isotropic Core Layers ........... 33

V. A SIMPLY SUPPORTED RECTANGULAR PLATE 35

5. 1 Example 1............. 35

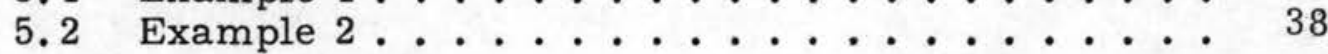

VI. SUMMARY AND CONCLUSIONS. . . . . . . . . 41

6. 1 Summary and Conclusions ......... 41

6.2 Comparison of Results ............ 42

A SELECTED BIBLIOGRAPHY . . . . . . . . . 43 


\section{LIST OF FIGURES}

Figure Page

1. A Cross Section of Plate ............. 4

2. Stresses on Typical Layers ........... 7

3. A Differential Plate Element. .......... 8

4. A Simply Supported Rectangular Plate. . . . . . 35 


\section{NOMENCLATURE}

The following symbols have been adopted for use in the thesis:

A, B, C . . . components of first variation of auxiliary functional;

D....... flexural rigidity;

$\mathrm{E}_{\mathrm{i}} \ldots \ldots$ modulus of elasticity of ith facing membrane layer;

$\mathrm{F}_{\mathrm{D}}, \mathrm{F}_{\mathrm{Z}}, \mathrm{F}_{\mathrm{S}} \ldots \quad$ property coefficients of plate;

$\mathrm{G}_{\mathrm{ixz}}, \mathrm{G}_{\mathrm{iyz}} \ldots$ moduli of rigidity of ith core layer;

$G, G_{x}, G_{y} \ldots$ property coefficients of plate;

$\mathrm{K}_{\mathrm{X}}, \mathrm{K}_{\mathrm{y}} \ldots \ldots \quad$ property coefficients of plate;

$M_{x}, M_{y}, M_{x y} \cdot$ moment stress resultants;

$\mathrm{N}_{\mathrm{x}}, \mathrm{N}_{\mathrm{y}}, \mathrm{N}_{\mathrm{xy}} \ldots$ face-parallel stress resultants;

P. . . .... load function normal to the plate;

$\mathrm{Q}_{\mathrm{x}}, \mathrm{Q}_{\mathrm{y}} \ldots . . \quad$ transverse shear stress resultants;

R . . . . . . total transverse resultant;

S...... property coefficient of plate;

U....... strain energy;

$\mathrm{W}^{*} \ldots \ldots$ work done on the part of boundary where displacements are prescribed;

$\bar{X}, \bar{Y}, \bar{Q}, \bar{M}_{x}, \bar{M}_{y} \quad$ total resultants in a specific direction along the boundary;

a,b..... plate dimensions;

c...... boundary;

$c_{d} \ldots \ldots$ the part of boundary where displacements are specified;;

$h_{j} \ldots . . \quad$ thickness of $j$ th core layer; 
i...... index, designates ith facing membrane layer;

j...... index, designates jth core layer;

n ...... total number of layers;

s....... length;

$t_{i} \ldots \ldots$ thickness of $i$ th facing membrane layer;

$\mathrm{u}, \mathrm{v}, \mathrm{w} \ldots$ displacements;

$\mathrm{x}, \mathrm{y}, \mathrm{z} \ldots$ coordinates;

$z_{i} \ldots \ldots$ distance measured from $x y$-plane to middle plane of ith membrane layer;

$\bar{z} \ldots \ldots$ property coefficient, defining position of weighted neutral surface;

$\pi^{*} \ldots \ldots$ complementary energy;

$\pi^{* *}$. . . . a auxiliary functional;

$\alpha, \beta \ldots$ generalized displacements;

$\delta \ldots \ldots . .$. first variation;

$\lambda_{1}, \lambda_{2}, \ldots \lambda_{13} \cdot \quad$ Lagrangian multipliers;

$\nu_{i} \ldots \ldots$ Poisson's ratio for ith facing membrane layer;

$\nu_{D}, \varphi, \nu_{S} \ldots \quad$ property coefficients of plate;

$\sigma_{\text {ix }}, \sigma_{i y}, \sigma_{i x y} \cdots \quad$ face-parallel stresses at ith facing membrane layer;

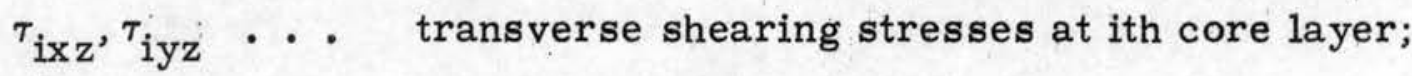

$\nabla^{2} \ldots$ Laplacian operator;

$\nabla^{4} \ldots \ldots \nabla^{2} \nabla^{2}$ and

$\nabla^{6} \ldots \nabla^{2} \nabla^{2} \nabla^{2}$.......

Additional symbols used in the example problems are defined when they appear and are not listed. 


\section{CHAPTER I}

\section{INTRODUCTION}

\subsection{General}

Sandwich constructions are characterized by different material properties between facing layers and core layers. The facing materials have relatively high moduli of elasticity and low moduli of rigidity as compared with the core materials. In this investigation the facing materials are considered to be homogeneous and isotropic, and the core materials homogeneous and or thotropic. All displacements are defined on a weighted neutral surface whose location will be given in the next chapter.

In addition to the above general description, the following assumptions are essential for this analysis:

(1) The material of each layer is elastic and follows Hooke's law.

(2) The transverse rigidities of the core materials are relatively high compared to the facing materials, i. e., transverse shear forces are completely taken by the core layers.

(3) The core stiffnesses associated with face-parallel stresses are neglected.

(4) The facing layers are thin compared with the core layers, i.e., the facing layers act as membranes.

(5) The total thickness of the multilayer plate is small compared 
with the other dimensions.

(6) Prior to buckling the deformations are small.

(7) At any section of the plate the transverse deflection of each layer is the same as that of the weighted neutral surface.

(8) No bond failure may occur prior to buckling of the plate.

(9) Local buckling is not considered.

(10) Temperature effect is neglected.

The governing differential equations for the stability of multilayer sandwich plates are derived by means of a variational method and the minimizing principle. The problem is formulated in a complete Lagrange form and the minimizing of the functional maps the general state of stresses to the one which satisfies the compatibility conditions. Once the set of Euler equations is obtained, the stress resultant - generalized displacement relations may be found and henceforth lead to the governing differential equations. A discussion of the effect of unequal Poisson's ratios in the facing layers and the orthotropic moduli of rigidity in the core layers is also included.

The letter symbols adopted for use in this thesis are defined where they first appear and are listed in the Nomenclature.

\subsection{Historical Notes}

The analytical study of structural members composed of sandwich construction becomes increasingly important with the developments of modern technology and the introduction of new materials. The majority of the past efforts connected with this work have been confined to single core construction with two facing layers. 
The general solution for bending of sandwich plates was presented by $\mathrm{E}$. Reissner $(5,6)$. He considered a plate consisting of a core with two facing membranes identical both in thickness and elastic properties, and assumed that the face-parallel stresses in the core layer and the variation of the stresses over the thickness of the facing layers were negligible. This assumes that the sandwich is a thin plate composed of a core layer of high transverse rigidity and low stiffnesses associated with the face-parallel stresses and that the facing layers act as membranes. Since Reissner's work many extensions of the theory have been presented ${ }^{(1,2)}$. One of the more significant extensions to the theory was the one presented by S. Cheng ${ }^{(3)}$ in which he treated the bending of sandwich plates with orthotropic core. The problems were formulated either by minimizing the complementary energy with the stress resultants taken as variables or by minimizing the potential energy with the displacements taken as variables.

The problem of multilayer sandwich plates was less explored. Recently a theory of bending was presented by B. D. Liaw ${ }^{(4)}$. Based on Reissner-Cheng assumptions, he formulated the problem in terms of the complementary energy with stresses taken as independent variables and stress resultants as dependent variables, and developed a general Lagrange-Navier type equation for the multilayer plates with equal Poisson's ratios for all facing membrane layers and orthotropic core layers. 
CHAPTER II

GENERAL ANALYSIS

\subsection{Statement of the Problem}

The mathematical model considered is a rectangular plate consisting of two core layers of thickness $h_{1}$ and $h_{2}$ and three facing membrane layers of thickness $t_{1}, t_{2}$ and $t_{3}$. Each facing membrane layer is assumed to be isotropic and homogeneous and possesses different elastic properties, while each core layer is orthotropic and also possesses different elastic properties. Let the $x y$-plane coincide with the weighted neutral surface at the undeformed position, with zaxis normal to this plane. Also let $z_{1}, z_{2}$ and $z_{3}$ be the distances measured from the $x y$-plane to the middle plane of each facing membrane layer respectively (Fig. 1). The weighted neutral surface of

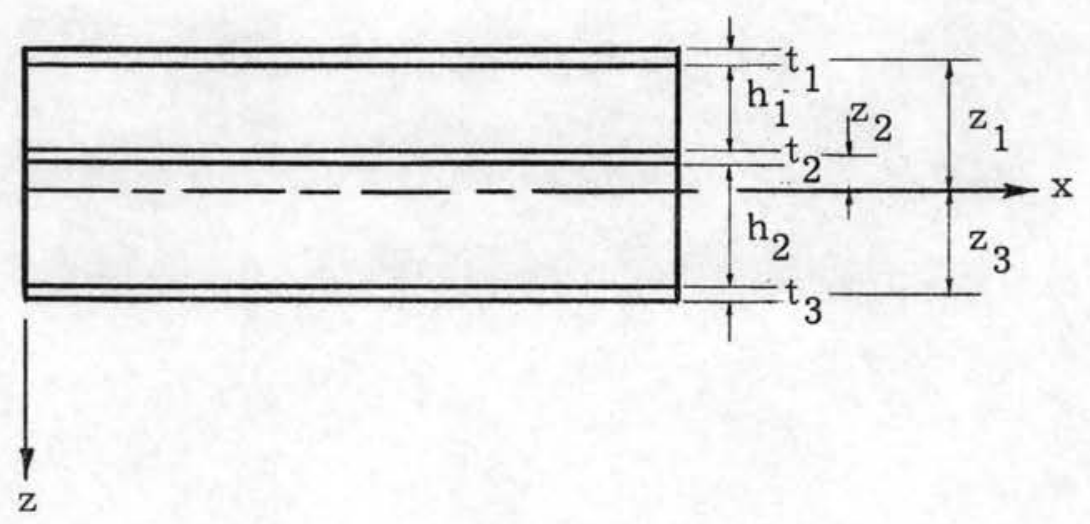

Figure 1 - A Cross Section of Plate 
the multilayer sandwich plate is at the position such that

$$
\sum_{i=1}^{3} \frac{E_{i} t_{i} z_{i}}{1-\nu_{i}^{2}}=0
$$

where $E_{i}$ and $\nu_{i}$ are the modulus of elasticity and Poisson's ratio of the ith facing membrane layer respectively.

The problem is then to develop the governing differential equations for the stability of multilayer sandwich plates. Though the model adopted is a five-layer plate, the final result is valid for any finite number of layers.

\subsection{Stress Resultants and Equilibrium Equations}

In accordance with the assumptions made previously that faceparallel stresses of core layers and the variations of stresses over the facing membrane layers are negligible, the stress resultants may be defined as follows:

$$
\begin{aligned}
& M_{x}=\sum_{i=1}^{3} \sigma_{i x} t_{i} z_{i} \\
& M_{y}=\sum_{i=1}^{3} \sigma_{i y i} t_{i} \\
& M_{x y}=\sum_{i=1}^{3} \sigma_{i x y} t_{i} z_{i}
\end{aligned}
$$




$$
\begin{aligned}
& N_{x}=\sum_{i=1}^{3} \sigma_{i x} t_{i} \\
& N_{y}=\sum_{i=1}^{3} \sigma_{i y}{ }^{t_{i}} \\
& N_{x y}=\sum_{i=1}^{3} \sigma_{i x y{ }^{t}} \\
& Q_{x}=\sum_{j=1}^{2} \tau_{j x z_{j} h_{j}} \\
& Q_{y}=\sum_{j=1}^{2} \tau_{j y z^{h}}
\end{aligned}
$$

where

$\mathrm{M}_{\mathrm{x}}\left(\mathrm{M}_{\mathrm{y}}\right)$ designates the bending moment about $\mathrm{y}(\mathrm{x})$ axis, $\mathrm{M}_{\mathrm{xy}}\left(\mathrm{M}_{\mathrm{yx}}\right)$ the twisting moment about $\mathrm{x}(\mathrm{y})$ axis, $\mathrm{N}_{\mathrm{x}}\left(\mathrm{N}_{\mathrm{y}}\right) \quad$ the normal force on the $\mathrm{x}(\mathrm{y})$ face, $\mathrm{N}_{\mathrm{xy}}\left(\mathrm{N}_{\mathrm{yx}}\right)$ the shear force parallel to the plane of the plate on the $x(y)$ face,

$Q_{x}\left(Q_{y}\right) \quad$ the transverse shear force on the $x(y)$ face, $\sigma_{i x}\left(\sigma_{i y}\right)$ the normal stress on the ith membrane in $x(y)$ direction,

$\sigma_{i x y}\left(\sigma_{i y x}\right)$ the shearing stress parallel to the plane of the plate on the ith membrane in $\mathrm{y}(\mathrm{x})$ direction, $\tau_{j x z}\left(\tau_{j y z}\right)$ the transverse shearing stress on the $x(y)$ face of the jth core (Fig. 2). 

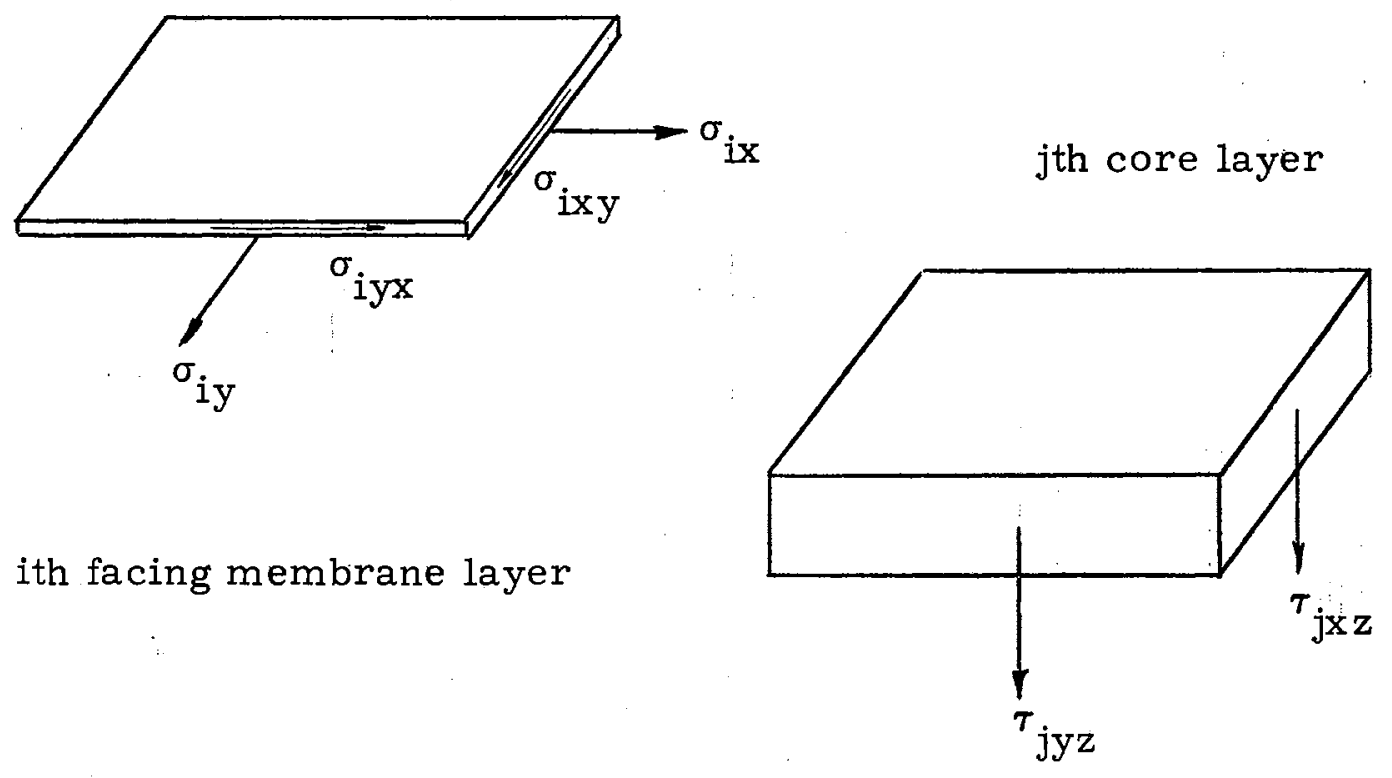

ith facing membrane layer

jth core layer

Figure 2 - Stresses on Typical Layers

Also the relations $\mathrm{M}_{\mathrm{xy}}=\mathrm{M}_{\mathrm{yx}}, \mathrm{N}_{\mathrm{xy}}=\mathrm{N}_{\mathrm{yx}}$ and $\sigma_{\mathrm{ixy}}=\sigma_{\mathrm{iyx}}$ are retained.

Equilibrium of forces and moments acting on a differential plate element (Fig. 3) yield the following equations:

$$
\begin{aligned}
& N_{x, x}+N_{y x, y}=0 \\
& N_{y, y}+N_{x y, x}=0 \\
& Q_{x, x}+Q_{y, y}+P+\left(N_{x} w_{, x}+N_{y x} w_{, y}\right), x+\left(N_{y} w_{, y}+N_{x y} w^{2}\right)_{, y}=0 \\
& M_{x, x}+M_{y x, y}-Q_{x}=0 \\
& M_{y, y}+M_{x y, x}-Q_{y}=0
\end{aligned}
$$

where comma means to take partial derivative of the quantity in front of it with respect to the following subscripts, and $P$ is the intensity 


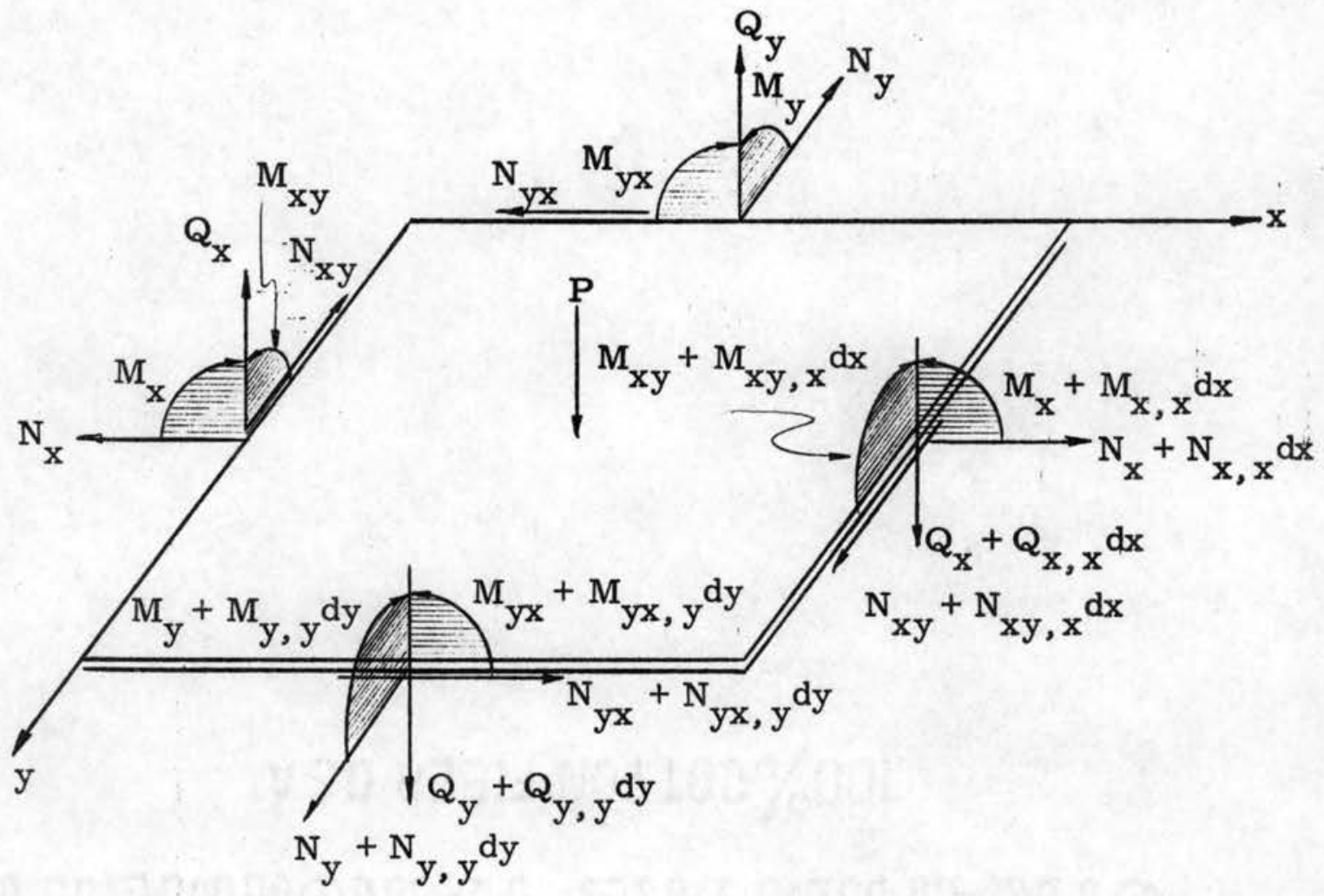

Figure 3 - A Differential Plate Element

of transverse load applied on the differential plate element. Equations (10), (11) and (12) may be combined into one equation:

$$
Q_{x, x}+Q_{y, y}+R=0
$$

where

$$
R=P+N_{x} w, x x+N_{y}{ }^{w}, y y+2 N_{x y}{ }^{w}, x y
$$

\section{$\underline{2.3 \text { Complementary Energy }}$}

Considering a rectangular plate of the dimensions $a$ by $b$, the strain energy stored in the system may be expressed in terms of 
stresses as:

$$
\begin{aligned}
U=\frac{1}{2} \int_{0}^{b} \int_{0}^{a}\left\{\sum_{i=1}^{3}\left[\frac{t_{i}}{E_{i}}\left(\sigma_{i x}^{2}+\sigma_{i y}^{2}-2 \nu_{i} \sigma_{i x} \sigma_{i y}\right)+\frac{2 t_{i}\left(1+\nu_{i}\right)}{E_{i}} \sigma_{i x y}^{2}\right]\right. \\
\left.+\sum_{j=1}^{2}\left[\frac{h_{j}}{G_{j x z}} \tau_{j x z}^{2}+\frac{h_{j}}{G_{j y z}} \tau_{j y z}^{2}\right]\right\} d x d y
\end{aligned}
$$

where $G_{j x z}\left(G_{j y z}\right)$ is the shear modulus of rigidity in $x z(y z)$ plane of the jth core layer.

Let $u, v, w, \alpha$ and $\beta$ be the generalized displacements at the boundary; then the work which the surface stresses do over that portion of the surface where the displacements are prescribed is

$$
\begin{aligned}
W^{*}=\int_{c_{d}}[\bar{X} u & \left.+\bar{Y}_{v}+\bar{X}_{w}, x+\bar{Y}_{w}, y+\bar{Q}\right) w \\
& \left.+\bar{M}_{x} \alpha+\bar{M}_{y} \beta\right] d s .
\end{aligned}
$$

where the capital bar letters indicate the total resultants in a specific direction along the boundary, for example, $\overline{\mathrm{X}}$ represents $\mathrm{N}_{\mathrm{x}}$ on $\mathrm{x}=0, \mathrm{x}=\mathrm{a}$ and $\mathrm{N}_{\mathrm{yx}}$ on $\mathrm{y}=0, \mathrm{y}=\mathrm{b}$ and $\mathrm{c}_{\mathrm{d}}$ designates the boundary where displacements are specified.

Then the complementary energy of the plate is

$$
\pi^{*}=\mathrm{U}-\mathrm{W}^{*} \text {. }
$$

Thus the problem becomes one of seeking the conditions for the extremum of the functional $\pi^{*}$ subjected to the constraint conditions of equations (2) to (14). 
$\underline{2.4 \quad \text { Auxiliary Functional }}$

Introducing thirteen Lagrangian multipliers $\lambda_{1}, \lambda_{2}, \ldots, \lambda_{13}$, the auxiliary functional, whose integrand consisting of the terms of complementary energy and the constraint equations multiplied by the Lagrangian multipliers, can be formulated as follows:

$$
\begin{aligned}
\pi^{* *}= & \int_{0}^{b} \int_{0}^{a}\left\{\sum_{i=1}^{3}\left[\frac{t_{i}}{2 E_{i}}\left(\sigma_{i x}^{2}+\sigma_{i y}^{2}-2 \nu_{i} \sigma_{i x} \sigma_{i y}\right)+\frac{t_{i}\left(1+\nu_{i}\right)}{E_{i}} \sigma_{i x y}^{2}\right]\right. \\
& +\frac{1}{2} \sum_{j=1}^{2}\left[\frac{h_{j}}{G_{j x z}} \tau_{j x z}^{2}+\frac{h_{j}}{G_{j y z}} \tau_{j y z}^{2}\right] \\
& +\lambda_{1}\left(M_{x}-\sum_{i=1}^{3} \sigma_{i x} t_{i} z_{i}\right) \\
& +\lambda_{2}\left(M_{y}-\sum_{i=1}^{3} \sigma_{i y} t_{i} z_{i}\right) \\
& +\lambda_{3}\left(M_{x y}-\sum_{i=1}^{3} \sigma_{i x y} t_{i} z_{i}\right) \\
& +\lambda_{5}\left(N_{y}-\sum_{i=1}^{3} \sigma_{i y} t_{i}\right) \\
&
\end{aligned}
$$




$$
\begin{aligned}
& +\lambda_{6}\left(\mathrm{~N}_{\mathrm{xy}}-\sum_{i=1}^{3} \sigma_{i x y} t_{i}\right) \\
& +\lambda_{7}\left(Q_{x}-\sum_{j=1}^{2} \tau_{j x z} h_{j}\right) \\
& +\lambda_{8}\left(Q_{y}-\sum_{j=1}^{2} \tau_{j y z} h_{j}\right) \\
& +\lambda_{9}\left(N_{x, x}+N_{y x ; y}\right) \\
& +\lambda_{10}\left(\mathrm{~N}_{\mathrm{y}, \mathrm{y}}+\mathrm{N}_{\mathrm{xy}, \mathrm{x}}\right) \\
& +\lambda_{11}\left[Q_{x, x}+Q_{y, y}+P+\left(N_{x} w_{, x}+N_{y x} w, y\right), x\right. \\
& +\left(N_{y} w, y+N_{x y} w, x^{w}, y\right] \\
& +\lambda_{12}\left(M_{x, x}+M_{y x, y}-Q_{x}\right) \\
& \left.+\lambda_{13}\left(M_{y, y}+M_{x y, x}-Q_{y}\right)\right\} d x d y \\
& -\int_{c_{d}}\left[\bar{X} u+\bar{Y}_{v}+\left(\bar{X}_{w}{ }_{, x}+\bar{Y}_{w}, y+\bar{Q}\right) w+\bar{M}_{x} \alpha+\bar{M}_{y} \beta\right] d s
\end{aligned}
$$

It is obvious that the Lagrangian multipliers have physical meanings. By the law of dimensional homogenity, the Lagrangian multipliers are some sort of displacements. 


\subsection{Compatibility Equations}

The well known principle of complementary energy states that for all stresses satisfying the equilibrium conditions, the actual state of stress, i.e., the stresses which satisfy the compatibility equations, is such that the complementary energy $\pi^{*}$ assumes a stationary value. For problems with small strains and displacements, it can be shown ${ }^{(20)}$ that $\pi^{*}$ is a minimum. In order to have extrema for the functional $\pi^{*}$ subjected to the constraint conditions, the necessary and sufficient condition is that the first variation of the auxiliary functional must vanish, $i_{0} e_{0}, \delta \pi^{* * *}=0$. Thus the condition $\delta \pi^{* * *}=0$ furnishes the set of compatibility equations.

Taking the first variation and collecting terms, the following expression is obtained:

$$
\delta \pi^{* * *}=A+B+C=0
$$

where

$$
\begin{gathered}
A=\int_{0}^{b} \int_{0}^{a} \sum_{i=1}^{3}\left\{\delta \sigma_{i x}\left[\frac{t_{i}}{E_{i}}\left(\sigma_{i x}-\nu_{i} \sigma_{i y}\right)-\lambda_{1} t_{i} z_{i}-\lambda_{4} t_{i}\right]\right. \\
+\delta \sigma_{i y}\left[\frac{t_{i}}{E_{i}}\left(\sigma_{i y}-\nu_{i} \sigma_{i x}\right)-\lambda_{2} t_{i} z_{i}-\lambda_{5} t_{i}\right] \\
\left.+\delta \sigma_{i x y}\left[\frac{2 t_{i}\left(1+\nu_{i}\right)}{E_{i}} \sigma_{i x y}-\lambda_{3} t_{i} z_{i}-\lambda_{6} t_{i}\right]\right\} \\
+\sum_{j=1}\left\{\delta \tau_{j x z}\left(\frac{h_{j}}{G_{j x z}} \tau_{j x z}-\lambda_{7} h_{j}\right)\right.
\end{gathered}
$$




$$
\begin{aligned}
& \left.+\delta \tau_{j y z}\left(\frac{h_{j}}{G_{j y z}} \tau_{j y z}-\lambda_{8} h_{j}\right)\right\} d x d y:, \\
& B=\int_{0}^{b} \int_{0}^{a}\left\{\lambda_{1} \delta M_{x}+\lambda_{12} \delta M_{x, x}\right. \\
& +\lambda_{2} \delta M_{y}+\lambda_{13} \delta M_{y, y} \\
& +\lambda_{3} \delta M_{x y}+\lambda_{12} \delta M_{x y, y}+\lambda_{13} \delta M_{x y, x} \\
& +\lambda_{4} \delta N_{x}+\lambda_{9} \delta N_{x, x}+\lambda_{11}\left(w_{, x} \delta N_{x}\right), x \\
& +\lambda_{5} \delta \mathrm{N}_{\mathrm{y}}+\lambda_{10} \delta \mathrm{N}_{\mathrm{y}, \mathrm{y}}+\lambda_{11}\left(\mathrm{w}, \mathrm{y}^{\left.\delta \mathrm{N}_{\mathrm{y}}\right)}, \mathrm{y}\right. \\
& +\lambda_{6} \delta N_{x y}+\lambda_{9} \delta N_{x y, y}+\lambda_{10} \delta N_{x y, x} \\
& +\lambda_{11}\left(\mathrm{w}, \mathrm{y}^{\left.\delta \mathrm{N}_{\mathrm{xy}}\right), \mathrm{x}}+\lambda_{11}\left(\mathrm{w}, \mathrm{x} \delta \mathrm{N}_{\mathrm{xy}}\right), \mathrm{y}\right. \\
& +\left(\lambda_{7}-\lambda_{12}\right) \delta Q_{x}+\lambda_{11} \delta Q_{x, x} \\
& \left.+\left(\lambda_{8}-\lambda_{13}\right) \delta Q_{y}+\lambda_{11} \delta Q_{y, y}\right\} d x d y \\
& C=-\int_{c_{d}}[u \delta \bar{X}+v \delta \bar{Y}+w(w, x \delta \bar{X}+w, y \delta \bar{Y}+\delta \bar{Q}) \\
& \left.+\alpha \delta \overline{\mathrm{M}}_{\mathrm{x}}+\beta \delta \overline{\mathrm{M}}_{\mathrm{y}}\right] \mathrm{d} \mathbf{s}
\end{aligned}
$$

The vanishing of $\delta \pi^{* *}$ requires the individual vanishing of A, B, and C. By the fundamental lemma of calculus of variations, the vanishing of $A$ furnishes thirteen Euler equations which are the compatibility equations. They are: 


$$
\begin{array}{lc}
\frac{t_{i}}{E_{i}}\left(\sigma_{i x}-\nu_{i} \sigma_{i y}\right)-\lambda_{1} t_{i} z_{i}-\lambda_{4} t_{i}=0 & i=1,2,3 \\
\frac{t_{i}}{E_{i}}\left(\sigma_{i y}-\nu_{i} \sigma_{i x}\right)-\lambda_{2} t_{i} z_{i}-\lambda_{5} t_{i}=0 & i=1,2,3 \\
\frac{2 t_{i}\left(1+\nu_{i}\right)}{E_{i}} \sigma_{i x y}-\lambda_{3} t_{i} z_{i}-\lambda_{6} t_{i}=0 & i=1,2,3 \\
\frac{1}{G_{j x z}} \tau_{j x z}-\lambda_{7}=0 & j=1,2 \\
\frac{1}{G_{j y z} \tau_{j y z}-\lambda_{8}=0} & j=1,2
\end{array}
$$

Thus the stresses may be written in terms of the Lagrangian multi-.: pliers:

$$
\begin{array}{ll}
\sigma_{i x}=\frac{E_{i}}{1-\nu_{i}^{2}}\left[z_{i}\left(\lambda_{1}+\nu_{i} \lambda_{2}\right)+\left(\lambda_{4}+\nu_{i} \lambda_{5}\right)\right] & i=1,2,3 \\
\sigma_{i y}=\frac{E_{i}}{1-\nu_{i}^{2}}\left[z_{i}\left(\lambda_{2}+\nu_{i} \lambda_{1}\right)+\left(\lambda_{5}+\nu_{i} \lambda_{4}\right)\right] & i=1,2,3 \\
\sigma_{i x y}=\frac{E_{i}}{2\left(1+\nu_{i}\right)}\left(z_{i} \lambda_{3}+\lambda_{6}\right) & i=1,2,3 \\
\tau_{j x z}=G_{j x z} \lambda_{7} & j=1,2 \\
\tau_{j y z}=G_{j y z} \lambda_{8} & j=1,2
\end{array}
$$




\subsection{Lagrangian Multipliers}

Integrating by parts equation ( $21 \mathrm{~b})$, then adding the results to equation $(21 \mathrm{c})$, and recalling from equation (21) that the sum should vanish:

$$
\begin{aligned}
& \mathrm{B}+\mathrm{C}=\int_{0}^{\mathrm{b}} \int_{0}^{\mathrm{a}}\left\{\delta \mathrm{M}_{\mathrm{x}}\left(\lambda_{1}-\lambda_{12, \mathrm{x}}\right)\right. \\
& +\delta M_{y}\left(\lambda_{2}-\lambda_{13, y}\right) \\
& +\delta M_{x y}\left(\lambda_{3}-\lambda_{12, y}-\lambda_{13, x}\right) \\
& +\delta N_{x}\left(\lambda_{4}-\lambda_{9, x}-\lambda_{11, x} w, x\right) \\
& +\delta \mathrm{N}_{\mathrm{y}}\left(\lambda_{5}-\lambda_{10, \mathrm{y}}-\lambda_{11, \mathrm{y}}{ }^{\mathrm{w}}, \mathrm{y}\right) \\
& +\delta N_{x y}\left(\lambda_{6}-\lambda_{9, y}-\lambda_{10, x}-\lambda_{11, x} w_{, y}-\lambda_{11, y}{ }_{, x}\right) \\
& +\delta Q_{x}\left(\lambda_{7}-\lambda_{11, x}-\lambda_{12}\right) \\
& \left.+\delta Q_{y}\left(\lambda_{8}-\lambda_{11, y}-\lambda_{13}\right)\right\} d x d y \\
& +\int_{\mathrm{c}}\left[\lambda_{9} \delta \overline{\mathrm{X}}+\lambda_{10} \delta \overline{\mathrm{Y}}+\lambda_{11}(\mathrm{w}, \mathrm{x} \delta \overline{\mathrm{X}}+\mathrm{w}, \mathrm{y} \delta \overline{\mathrm{Y}}+\delta \overline{\mathrm{Q}})\right. \\
& \left.+\lambda_{12} \delta \overline{\mathrm{M}}_{\mathrm{x}}+\lambda_{13} \delta \overline{\mathrm{M}}_{\mathrm{y}}\right] \mathrm{ds} \\
& -\int_{c_{d}}[u \delta \bar{X}+v \delta \bar{Y}+w(w, x \delta \bar{X}+w, y \delta \bar{Y}+\delta \bar{Q}) \\
& \left.+\alpha \delta \overrightarrow{\mathrm{M}}_{\mathrm{x}}+\beta \delta \overline{\mathrm{M}}_{\mathrm{y}}\right] \mathrm{ds}=0
\end{aligned}
$$


Therefore, the area integral and the line integrals must vanish individually.

It may be observed that the first line integral of equation (32) vanishes on the part of the boundary where surface stresses are specified, hence it has a non-zero value only at that portion of the boundary where the displacements are prescribed, i.e., at $c_{d}$. Then on the boundary:

$$
\begin{aligned}
& \lambda_{9}=\mathrm{u} \\
& \lambda_{10}=\mathrm{v} \\
& \lambda_{11}=\mathrm{w} \\
& \lambda_{12}=\alpha \\
& \lambda_{13}=\beta
\end{aligned}
$$

Since equation (21) also holds for any part of the plate, it follows that the Lagrangian multipliers throughout the plate are related to the generalized displacements by equations (33) to (37).

Introducing equations (33) to (37) in the area integral of equation (32), the other eight Lagrangian multipliers may be expressed in terms of the generalized displacements:

$$
\begin{aligned}
& \lambda_{1}=\alpha, \mathrm{x} \\
& \lambda_{2}=\beta, \mathrm{y}
\end{aligned}
$$




$$
\begin{aligned}
& \lambda_{3}=\alpha, y+\beta, x \\
& \lambda_{4}=u_{, x}+w, x^{w}, x \\
& \lambda_{5}=v, y+w, y^{w}, y \\
& \lambda_{6}=v, x^{+u}, y+2 w, x^{w}, y \\
& \lambda_{7}=\alpha+w, x \\
& \lambda_{8}=\beta+w, y
\end{aligned}
$$

\subsection{Boundary Conditions}

From the line integrals of equation (32), the following quantities should take on the corresponding values at the boundaries $\mathrm{x}=0$ and $x=a$ :

$$
\begin{aligned}
& \mathrm{u} \text { or } \mathrm{N}_{\mathrm{x}} \\
& \mathrm{v} \text { or } \mathrm{N}_{\mathrm{xy}} \\
& \mathrm{w} \text { or } \mathrm{N}_{\mathrm{x}} \mathrm{w}_{, \mathrm{x}}+\mathrm{N}_{\mathrm{xy}} \mathrm{w}, \mathrm{y} \\
& \alpha \text { or } \mathrm{M}_{\mathrm{x}} \\
& \beta \text { or } \mathrm{M}_{\mathrm{xy}}
\end{aligned}
$$

and at the boundaries $y=0$ and $y=b$ :

$$
\begin{aligned}
& \mathrm{u} \text { or } \mathrm{N}_{\mathrm{yx}} \\
& \mathrm{v} \text { or } \mathrm{N}_{\mathrm{y}}
\end{aligned}
$$




$$
\begin{aligned}
& \text { w or } \mathrm{N}_{\mathrm{y}}{ }^{\mathrm{w}}, \mathrm{y}+\mathrm{N}_{\mathrm{yx}}{ }^{\mathrm{w}}, \mathrm{x} \\
& \alpha \text { or } \mathrm{M}_{\mathrm{yx}} \\
& \beta \text { or } \mathrm{M}_{\mathrm{y}}
\end{aligned}
$$

\subsection{General Analysis}

The purpose of this investigation is to find a general solution for the stability of multilayer sandwich plates. At the beginning, thirteen conditions are known: There are eight equations defining stress resultants in terms of stresses and five equilibrium equations in terms of stress resultants. Thus the problem is essentially to find the compatibility conditions and then the governing equations which satisfy both the thirteen known conditions and the compatibility conditions.

Two approaches appear to be adequate for the task. The first approach calls for the formulation of the complementary energy from which the Euler equations are obtained. Then these compatibility conditions can be solved simultaneously with the thirteen known conditions. The second approach introduces an auxiliary functional containing the complementary energy and the thirteen known conditions each multiplied by a corresponding Lagrangian multiplier. Since the known conditions are treated as constraint conditions, the set of Euler equations provided by the auxiliary functional represents the compatibility conditions subjected to the constraint of the thirteen known conditions; in other words, both the equilibrium equations and the stress resultantstress relations are incorporated in the Euler equations. The second approach takes full advantage of the elegant Lagrange formulation, 
reflects a deeper philosophy of structural mechanics, and is thus adopted.

For an $n$-layer sandwich plate, $\mathrm{n}=3,5,7 \ldots$ there are $\frac{1}{2}(5 n+1)$ stresses. Except for the fundamental case, where $n=3$, the number of stresses is always more than the number of equations given by the stress resultant-stress relations. A direct inversion of the stress resultant-stress relations for the stress-stress resultant relations is not feasible. The technique of taking stress resultants as independent variables in the formulation of an auxiliary functional, which has been employed by many investigators in the study of threelayer sandwich plates, is not applicable to sandwich plates composed of more than three layers. In this investigation, the stresses are taken as independent variables and the stress resultants as dependent variables。

The auxiliary functional approach is both general and unique. For an $n$-layer sandwich plate there are $21+\frac{1}{2}(5 n+1)$ unknowns: $\frac{1}{2}(5 n+1)$ stresses, eight stress resultants and thirteen Lagrangian multipliers. Also there are $21+\frac{1}{2}(5 n+1)$ conditions: $\frac{1}{2}(5 n+1)$ Euler equations, eight relations between Lagrangian multipliers, eight stress resultant-stress relations and five equilibrium equations. Introducing the thirteen Lagrangian multipliers has important physical significance. Their presence enables the known conditions to be treated as constraint conditions and also provides information which is necessary for the stress-generalized displacement relations. 
The successful definition of a proper reference surface, the weighted neutral surface, is essential to the problem. The location of the weighted neutral surface in a multilayer sandwich plate may not be recognized without elaborate exploration of the problem. Due to the proper choice of a reference surface, the elimination processes that lead to the governing equations are reduced substantially. 


\section{CHAPTER III}

\section{GOVERNING DIFFERENTIAL EQUATIONS}

\subsection{Property Coefficients}

For convenience, the following constants are defined:

$$
\begin{aligned}
& D=\sum_{i=1}^{3} \frac{E_{i} t_{i} z_{i}^{2}}{1-\nu_{i}^{2}} \\
& \bar{z}=\sum_{i=1}^{3} \frac{E_{i} t_{i} z_{i}}{1-\nu_{i}^{2}} \\
& S=\sum_{i=1}^{3} \frac{E_{i} t_{i}}{1-\nu_{i}^{2}} \\
& \nu_{D}=\frac{1}{D} \sum_{i=1}^{3} \frac{E_{i} t_{i} z_{i}^{2} \nu_{i}}{1-\nu_{i}^{2}} \\
& \varphi=\sum_{i=1}^{3} \frac{E_{i} t_{i} z_{i} \nu_{i}}{1-\nu_{i}^{2}} \\
& \nu_{S}=\frac{1}{S} \sum_{i=1}^{3} \frac{E_{i} t_{i} \nu_{i}}{1-\nu_{i}^{2}}
\end{aligned}
$$




$$
\begin{aligned}
& F_{D}=\sum_{i=1}^{3} \frac{E_{i} t_{i} z_{i}^{2}}{2\left(1+\nu_{i}\right)} \\
& F_{z}=\sum_{i=1}^{3} \frac{E_{i} t_{i} z_{i}}{2\left(1+\nu_{i}\right)} \\
& F_{S}=\sum_{i=1}^{3} \frac{E_{i} t_{i}}{2\left(1+\nu_{i}\right)} \\
& G_{x}=\sum_{j=1}^{2} G_{j x z} h_{j} \\
& G_{y}=\sum_{j=1}^{2} G_{j y z^{h}}
\end{aligned}
$$

Recalling the definition of weighted neutral surface, $\bar{z}=0$ 。

\subsection{Stress Resultants}

By substituting equations (27) to (31) in equations (2) to (9), stress resultants may be written in terms of Lagrangian multipliers:

$$
\begin{aligned}
& M_{x}=D\left(\lambda_{1}+\nu_{D} \lambda_{2}\right)+\varphi \lambda_{5} \\
& M_{y}=D\left(\lambda_{2}+\nu_{D} \lambda_{1}\right)+\varphi \lambda_{4} \\
& M_{x y}=F_{D} \lambda_{3}+F_{z^{\prime} \lambda_{6}} \\
& N_{x}=\varphi \lambda_{2}+S\left(\lambda_{4}+\nu_{S} \lambda_{5}\right)
\end{aligned}
$$




$$
\begin{aligned}
& \mathrm{N}_{\mathrm{y}}=\varphi \lambda_{1}+\mathrm{S}\left(\lambda_{5}+\nu_{\mathrm{S}} \lambda_{4}\right) \\
& \mathrm{N}_{\mathrm{xy}}=\mathrm{F}_{\mathrm{z}} \lambda_{3}+\mathrm{F}_{\mathrm{S}} \lambda_{6} \\
& \mathrm{Q}_{\mathrm{x}}=\mathrm{G}_{\mathrm{x}} \lambda_{7} \\
& \mathrm{Q}_{\mathrm{y}}=\mathrm{G}_{\mathrm{y}} \lambda_{8}
\end{aligned}
$$

From equations (44), (45), (55), and (56),

$$
\begin{aligned}
& \alpha=\frac{Q_{x}}{G_{x}}-w, x=-\left(w, x-\frac{Q_{x}}{G_{x}}\right) \\
& \beta=\frac{Q_{y}}{G_{y}}-w, y=-\left(w, y-\frac{Q_{y}}{G_{y}}\right)
\end{aligned}
$$

Hence the generalized displacements $\alpha$ and $\beta$ are the negative slopes (excluding shear effect) in $\mathrm{x}$ and $\mathrm{y}$ directions respectively. Introducing equations (38) to (45) in equations (49) to (56), the stress resultants may be written in terms of generalized displacements:

$$
\begin{aligned}
& M_{x}=D\left(\alpha, x+\nu_{D}^{\beta}, y\right)+\varphi(v, y+w, y, y) \\
& M_{y}=D\left(\beta, y+\nu_{D}{ }^{\alpha}, x^{\prime}\right)+\varphi\left(u, x+w, x^{w}, x\right) \\
& M_{x y}=F_{D}(\alpha, y+\beta, x)+F_{z}\left(v, x+u, y+2 w, x^{w}, y\right) \\
& N_{x}=\varphi \beta, y+S\left[u, x+w, x^{w}, x+\nu_{S}(v, y+w, y, y)\right] \\
& N_{y}=\varphi \alpha, x+S\left[v, y+w, y, y+\nu_{S}(u, x+w, x, w)\right]
\end{aligned}
$$




$$
\begin{aligned}
& N_{x y}=F_{z}(\alpha, y+\beta, x)+F_{S}\left(v, x+u_{, y}+2 w, x, y\right) \\
& Q_{x}=G_{x}(\alpha+w, x) \\
& Q_{y}=G_{y}(\beta+w, y)
\end{aligned}
$$

\subsection{Governing Differential Equations}

The governing differential equations for stability of multilayer sandwich plates may be obtained by substituting equations (59) through (66) into equations (10) to (14):

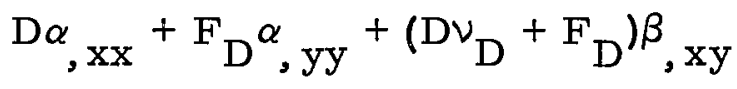

$$
\begin{aligned}
& +F_{z} u, y y,\left(\varphi+F_{z}\right) v, x y \\
& +2 F, w, x^{w}, y y+2\left(\varphi+F, z^{w}, y^{w}, x y-G_{x}(\alpha+w, x)=0\right. \\
& \mathrm{F}_{\mathrm{D}^{\beta}, \mathrm{xx}}+\mathrm{D} \beta, \mathrm{yy}+\left(\mathrm{D} \nu_{\mathrm{D}}+\mathrm{F}_{\mathrm{D}}\right) \alpha, \mathrm{xy}
\end{aligned}
$$

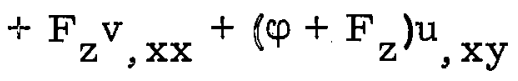

$$
\begin{aligned}
& +2 F_{z} w, y, x x+2\left(\varphi+F_{z}\right) w, x w, x y-G_{y}(\beta+w, y)=0 \\
& \mathrm{D}(\alpha, \mathrm{xxx}+\beta, \mathrm{yyy})+\left(\mathrm{D} \nu_{\mathrm{D}}+2 \mathrm{~F}_{\mathrm{D}}\right)(\alpha, \mathrm{xyy}+\beta, \mathrm{xxy}) \\
& +\left(\varphi+2 F_{z}\right)(u, x y y+v, x x y) \\
& +2 F_{z}\left(w, x^{w}, x y y+w, y^{w}, x x y+2 w, x x^{w}, y y^{\prime}\right. \\
& +2\left(\varphi+F_{z}\right)\left(w, x^{w}, x y y^{+} w_{x} y^{w}, x x y+2 w, x y, x y\right)+R=0(69)
\end{aligned}
$$




$$
\begin{aligned}
& \mathrm{F}_{\mathrm{z}}^{\alpha}, \mathrm{yy}+\left(\varphi+\mathrm{F}_{\mathrm{z}}\right) \beta, \mathrm{xy} \\
& +\mathrm{Su}, \mathrm{xx}+\mathrm{F}_{\mathrm{S}^{\mathrm{u}}, \mathrm{yy}}+\left(\mathrm{S} \mathrm{v}_{\mathrm{S}}+\mathrm{F}_{\mathrm{S}}\right) \mathrm{v}, \mathrm{xy} \\
& +2 w, x\left(S w, x x+F_{S} w, y y\right)+2 w, y^{w}, x y\left(S \nu_{S}+F_{S}\right)=0 \\
& F_{z}{ }^{\beta}, x x+\left(\varphi+F_{z}\right) \alpha, x y \\
& +\mathrm{F}_{\mathrm{S}^{\mathrm{v}}, \mathrm{xx}}+\mathrm{Sv}, \mathrm{yy}+\left(\mathrm{S} \mathrm{S}_{\mathrm{S}}+\mathrm{F}_{\mathrm{S}}\right) \mathrm{u}, \mathrm{xy} \\
& \left.+2 w, y^{\left(F_{S} w\right.}, x x+S w, y y\right)+2 w, x^{w}, x y\left(S \nu_{S}+F_{S}\right)=0
\end{aligned}
$$

\subsection{Approximate Solution}

It is possible to solve the set of nonlinear differential equations (67) to (71) by the method of successive approximations. First an approximate solution is obtained by some convenient method, then this solution is introduced into the original equations, and the error may be distributed and minimized. This process may be repeated several times until the error is within a preassigned tolerable range.

An approximation solution is suggested by neglecting certain terms in the governing differential equations. By comparing the order of magnitude, it is obvious that $\mathrm{F}_{\mathrm{z}}$ and $\varphi$ are small for practical materials whose Poisson's ratios fall between 0.30 to 0.34 . If $\mathrm{F}_{\mathrm{z}}$ and $\varphi$ are neglected, the approximate equations take the form:

$$
\begin{aligned}
& \mathrm{D} \alpha, \mathrm{xx}+\mathrm{F}_{\mathrm{D}} \alpha, \mathrm{yy}+\left(\mathrm{D} \nu_{\mathrm{D}}+\mathrm{F}_{\mathrm{D}}\right) \beta, \mathrm{xy}-\mathrm{G}_{\mathrm{x}}(\alpha+\mathrm{w}, \mathrm{x})=0 \\
& \mathrm{~F}_{\mathrm{D}}{ }^{\beta, \mathrm{xx}}+\mathrm{D} \beta, \mathrm{yy}+\left(\mathrm{D} \nu_{\mathrm{D}}+\mathrm{F}_{\mathrm{D}}\right) \alpha, \mathrm{xy}-\mathrm{G}_{\mathrm{y}}(\beta+\mathrm{w}, \mathrm{y})=0 \\
& \mathrm{D}\left(\alpha, \mathrm{xxx}+\beta_{, \mathrm{yyy}}\right)+\left(\mathrm{D} \nu_{\mathrm{D}}+2 \mathrm{~F}_{\mathrm{D}}\right)\left(\alpha, \mathrm{xyy}+{ }_{, \mathrm{xxy}}\right)+\mathrm{R}=0
\end{aligned}
$$


By neglecting $\mathrm{F}_{\mathrm{z}}$ and $\varphi$, the equations are simplified considerably. This simplification not only uncouples equations (67a), (68a), and (69a) from $u$ and $v$, but also linearizes the equations. It is felt that equations (67a), (68a), and (69a) would give fairly good approximate results. If the solution furnished by these equations is not satisfactory, then a successive approximation technique may be applied. 


\section{CHAPTER IV}

\section{SPECIAIIZATION FOR EQUAL POISSON'S RATIOS}

\section{1 Poisson's Ratio}

The theory presented so far is for a general case in which each facing membrane "layer may have a different Poisson's ratio. Due to the presence of a different Poisson's ratio for each facing membrane layer, the governing differential equations may not be simplified to a favorable form. It is observed that the values of Poisson's ratio may fall in a narrow region for materials with appreciably different moduli of elasticity. This is particularly true for materials that are generally used as facing membrane layers, such as steel $\left(E=29 \times 10^{6}\right.$ psi. $\nu=0.30)$ and aluminum $\left(E=10 \times 10^{6}\right.$ psi, $\left.\nu=0.33\right)$ 。

In the following, an analysis is presented for the case of equal Poisson's ratios for all facing membrane layers. It is believed that this specialization represents fairly good approximation for the general case.

\section{$\underline{4.2}$ Stress Resultants}

For the case of all facing membrane layers having an equal Poisson's ratio,

$$
\nu_{1}=\nu_{2}=\nu_{3}=\nu
$$


the property coefficients defined by equation (55) become:

$$
\begin{aligned}
& D:=\frac{1}{1-\nu^{2}} \sum_{i=1}^{3} E_{i} t_{i} z_{i}^{2} \\
& \bar{z}=0 \\
& S=\frac{1}{1-v^{2}} \sum_{i=1}^{3} E_{i} t_{i} \\
& \nu_{D}=v \\
& \varphi=0 \\
& \nu_{S}=\nu \\
& F_{D}=\frac{1-\nu}{2} D \\
& F_{z}=0 \\
& F_{S}=\frac{1-\nu}{2} S \\
& G_{x}=\sum_{j=1}^{2} G_{j x z^{h}} \\
& G_{y}=\sum_{j=1}^{2} G_{j y z} h_{j} \text {. }
\end{aligned}
$$

And the stress resultants are:

$$
M_{x}=D(\alpha, x+\nu \beta, y)
$$




$$
\begin{aligned}
& M_{y}=D\left(\beta, y+\nu \alpha, x^{\prime}\right) \\
& M_{x y}=\frac{1-\nu}{2} D(\alpha, y+\beta, x) \\
& N_{x}=S\left[u, x+w, x^{w}, x+\nu\left(v, y+w, y^{w}, y\right)\right] \\
& N_{y}=S\left[v, y+w, y^{w}, y+\nu\left(u, x+w, x^{w}, x^{\prime}\right)\right] \\
& N_{x y}=\frac{1-\nu}{2} S\left(v, x+u, y+2 w, x^{w}, y\right) \\
& Q_{x}=G_{x}(\alpha+w, x) \\
& Q_{y}=G_{y}(\beta+w, y)
\end{aligned}
$$

It is readily recognized that the property coefficient $D$ is the equivalent flexural rigidity of the multilayer sandwich plate.

Making use of equations (57) and (58), equations (74), (75), and (76) may be expressed as

$$
\begin{aligned}
& M_{x}=D\left[\frac{Q_{x, x}}{G_{x}}+v \frac{Q_{y, y}}{G_{y}}-(w, x x+v w, y y)\right] \\
& M_{y}=D\left[\frac{Q y, y}{G_{y}}+v \frac{Q_{x, x}}{G_{x}}-(w, y y+v w, x x)\right] \\
& M_{x y}=\frac{1-\nu}{2} D\left[\frac{Q_{x, y}}{G_{x}}+\frac{Q_{y, x}}{G_{y}}-2 w, x y\right]
\end{aligned}
$$




\section{3 Governing Differential Equations}

Differentiate equation (74a) with respect to $x$, equation (76a) with respect to $\mathrm{y}$ and substitute into equation (13),

$$
Q_{x}=D\left[\frac{Q_{x, x x}}{G_{x}}+\frac{1-\nu}{2} \frac{Q_{x, y y}}{G_{x}}+\frac{1+\nu}{2} \frac{Q_{y, x y}}{G_{y}}-\nabla^{2} w, x\right]
$$

where $\nabla^{2}$ is the Laplacian operator. Similarly from equations (73a). (74a), and (14),

$$
Q_{y}=D\left[\frac{Q_{y, y y}}{G_{y}}+\frac{1-\nu}{2} \frac{Q_{y, x x}}{G_{y}}+\frac{1+\nu}{2} \frac{Q x, x y}{G_{x}}-\nabla^{2} w, y\right]
$$

Differentiate equation (82) with respect to $x$, equation (83) with respect to $y$ and substitute into equation (15),

$$
\nabla^{4} w=\frac{R}{D}+\nabla^{2}\left(\frac{\mathrm{x}, \mathrm{x}}{\mathrm{G}_{\mathrm{x}}}+\frac{\mathrm{Q}_{\mathrm{y}, \mathrm{y}}}{\mathrm{G}_{\mathrm{y}}}\right)
$$

Differentiate equation (82) with respect to $y$ and equation (83) with respect to $\mathrm{x}$ :

$$
\begin{aligned}
& Q_{x, y}=D\left[\frac{Q_{x, x x y}}{G_{x}}+\frac{1-\nu}{2} \frac{Q_{x, y y y}}{G_{x}}+\frac{1+\nu}{2} \frac{Q_{y, x y y}}{G y}-\nabla^{2} w, x y\right] \\
& Q_{y, x}=D\left[\frac{Q_{y, x y y}}{G}+\frac{1-\nu}{2} \frac{Q_{y, x x x}}{G}+\frac{1+\nu}{2} \frac{Q_{x, x x y}}{G_{x}}-\nabla^{2} w, x y\right.
\end{aligned}
$$

Subtract equation (86) from equation (85), 


$$
Q_{x, y}-Q_{y, x}=\frac{1-v}{2} D \nabla^{2}\left(\frac{Q x, y}{G_{x}}-\frac{Q y, x}{G_{y}}\right)
$$

Differentiate equation (87) with respect to $y$, equation (15) with respect to $\mathbf{x}$,

$$
\begin{aligned}
& Q_{x, y y}-Q_{y, x y}=\frac{1-\nu}{2} D \nabla^{2}\left(\frac{Q x, y y}{G_{x}}-\frac{Q_{y, x y}}{G_{y}}\right) \\
& -Q_{y, x y}=Q_{x, x x}+R, x
\end{aligned}
$$

Substitute equation (89) into equation (88),

$$
\frac{1-\nu}{2 G_{x}} D \nabla^{2} Q_{x, y y}+\frac{1-\nu}{2 G_{y}} D \nabla^{2} Q_{x, x x}-\nabla^{2} Q_{x}=R_{, x}-\frac{1-\nu}{2 G_{y}} D \nabla^{2} R, x(90)
$$

Let

$$
\begin{aligned}
& K_{x}=\frac{(1-v) D}{2 G_{x}} \\
& K_{y}=\frac{(1-v) D}{2 G_{y}}
\end{aligned}
$$

After rearranging, equation (90) may be written as:

$$
\mathrm{K}_{\mathrm{x}} \nabla^{4} \mathrm{Q}_{\mathrm{x}}+\left(\mathrm{K}_{\mathrm{y}}-\mathrm{K}_{\mathrm{x}}\right) \nabla^{2} \mathrm{Q}_{\mathrm{x}, \mathrm{xx}}-\nabla^{2} \mathrm{Q}_{\mathrm{x}}=\mathrm{R}, \mathrm{x}-\mathrm{K}_{\mathrm{y}} \nabla^{2} \mathrm{R}_{, \mathrm{x}}
$$

and similarly,

$$
K_{y} \nabla^{4} Q_{y}+\left(K_{x}-K_{y}\right) \nabla^{2} Q_{y, y y}-\nabla^{2} Q_{y}=R_{, y}-K_{x} \nabla^{2} R, y
$$


Equations $(84),(92)$, and (93) are the governing differential equations.

\section{$\underline{4.4 \quad \text { Deflection Surface }}$}

It is possible to develop a governing differential equation in terms of the deflection surface. Such an equation is of the same form as the Lagrange-Navier equation of classical homogeneous thin plates.

Differentiate equation (82) with respect to $\mathrm{x}$, equation (83)

with respect to $\mathrm{y}$ and add together,

$$
\mathrm{Q}_{\mathrm{x}, \mathrm{x}}+\mathrm{Q}_{\mathrm{y}, \mathrm{y}}=\mathrm{D}\left[\frac{1}{\mathrm{G}_{\mathrm{x}}} \nabla^{2} \mathrm{Q}_{\mathrm{x}, \mathrm{x}}+\frac{1}{\mathrm{G}_{\mathrm{y}}} \nabla^{2} \mathrm{Q}_{\mathrm{y}, \mathrm{y}}-\nabla^{4} \mathrm{w}\right]
$$

Substituting above expression into equation (15), then multiply by $\frac{1}{2}(1-\nu)$ and rearrange,

$$
\left(K_{x}-K_{y}\right) \nabla^{2} Q_{x, x}=\frac{(1-\nu) D}{2}\left(\nabla^{4} w-\frac{R}{D}\right)+K_{y} \nabla^{2} R
$$

That is,

$$
\nabla^{2} Q_{x, x}=\frac{(1-\nu) D}{2\left(K_{x}-K_{y}\right)}\left(\nabla^{4} w-\frac{R}{D}\right)+\frac{K y}{K_{x}-K_{y}} \nabla^{2} R
$$

Differentiate equation (92) with respect to $x$, making use of equation (95) and rearranging

$$
\begin{aligned}
& \mathrm{K}_{\mathrm{x}} \nabla^{6} \mathrm{w}+\left(\mathrm{K}_{\mathrm{y}}-\mathrm{K}_{\mathrm{x}}\right) \nabla^{4} \mathrm{w}_{, \mathrm{xx}}-\nabla^{4} \mathrm{w} \\
& =\frac{1}{\mathrm{D}}\left[-\frac{2 \mathrm{~K}_{\mathrm{x}} \mathrm{K}_{\mathrm{y}}}{1-\nu} \nabla^{4} \mathrm{R}+\left(\mathrm{K}_{\mathrm{x}}+\frac{2 \mathrm{~K}_{\mathrm{y}}}{1-\nu} \nabla^{2} \mathrm{R}+\frac{1+\nu}{1-\nu}\left(\mathrm{K}_{\mathrm{x}}-\mathrm{K}_{\mathrm{y}}\right) \mathrm{R}, \mathrm{xx}-\mathrm{R}\right]\right.
\end{aligned}
$$


Equation (96) is the governing differential equation in terms of the deflection surface. Another form of equation (96) in which $\mathbf{x}$ and $y$ are balanced is as follows:

$$
\begin{aligned}
& \mathrm{K}_{\mathrm{y}} \nabla^{4} \mathrm{w}, \mathrm{xx}+\mathrm{K}_{\mathrm{x}} \nabla^{4} \mathrm{w}, \mathrm{yy}-\nabla^{4} \mathrm{w} \\
& =\frac{1}{\mathrm{D}}\left[-\frac{2 \mathrm{~K}_{\mathrm{x}} \mathrm{K}}{1-\nu} \nabla^{4} \mathrm{R}+\left(\frac{2 \mathrm{~K}_{\mathrm{x}}}{1-\nu}+\mathrm{K}_{\mathrm{y}}\right) \mathrm{R}, \mathrm{xx}\right. \\
& \left.1-\left(\mathrm{K}_{\mathrm{x}}+\frac{2 \mathrm{~K}_{\mathrm{y}}}{1-\nu}\right) \mathrm{R}, \mathrm{yy}-\mathrm{R}\right]
\end{aligned}
$$

The governing differential equation may be written in a form similar to the Lagrange-Navier equation of classical homogenous thin plates:

$$
\begin{aligned}
& \left(1-\mathrm{K}_{\mathrm{y}} \frac{\partial^{2}}{\partial \mathrm{x}^{2}}-\mathrm{K}_{\mathrm{x}} \frac{\partial^{2}}{\partial \mathrm{y}^{2}}\right) \nabla^{4} \mathrm{w} \\
& =\left[1-\left(\frac{2 \mathrm{x}}{1-\nu}+\mathrm{K}_{\mathrm{y}}\right) \frac{\partial^{2}}{\partial \mathrm{x}^{2}}-\left(\mathrm{K}_{\mathrm{x}}+\frac{2 \mathrm{~K}}{1-\nu}\right) \frac{\partial^{2}}{\partial \mathrm{y}^{2}}+\frac{2 \mathrm{~K}_{\mathrm{x}} \mathrm{K}}{1-\nu} \nabla^{4}\right] \frac{\mathrm{R}}{\mathrm{D}}
\end{aligned}
$$

\subsection{Isotropic Core Layers}

For multilayer sandwich plates with isotropic core layers, the elastic constants become:

$$
\begin{aligned}
& G_{x}=G_{y}=G \\
& K_{x}=K_{y}=\frac{(1-\nu) D}{2 G}=K
\end{aligned}
$$

Then from equation (94)

$$
\frac{(1-\nu) D}{2}\left(\nabla^{4} w-\frac{R}{D}\right)+K \nabla^{2} R=0
$$


Thus the governing differential equation is

$$
\nabla^{4}{ }_{\mathrm{w}}=\frac{\mathrm{R}}{\mathrm{D}}-\frac{1}{\mathrm{G}} \nabla^{2} \mathrm{R}
$$




\section{CHAPTER V}

\section{A SIMPLY SUPPORTED RECTANGULAR PLATE}

Two examples of a simply supported rectangular plate are presented in this chapter. The first example treats a multilayer sandwich plate with unequal Poisson's ratios for each facing membrane layer by the linearized approximate equations. The second example illustrates a multilayer sandwich plate with equal Poisson's ratios for all facing membrane layers by the exact equation.

\section{1 Example 1}

A rectangular multilayer sandwich plate simply supported along all edges is subjected to a uniform distributed compressive load of intensity $P_{x}$ (Fig。4)。 Determine the critical load by the linearized approximate equations.

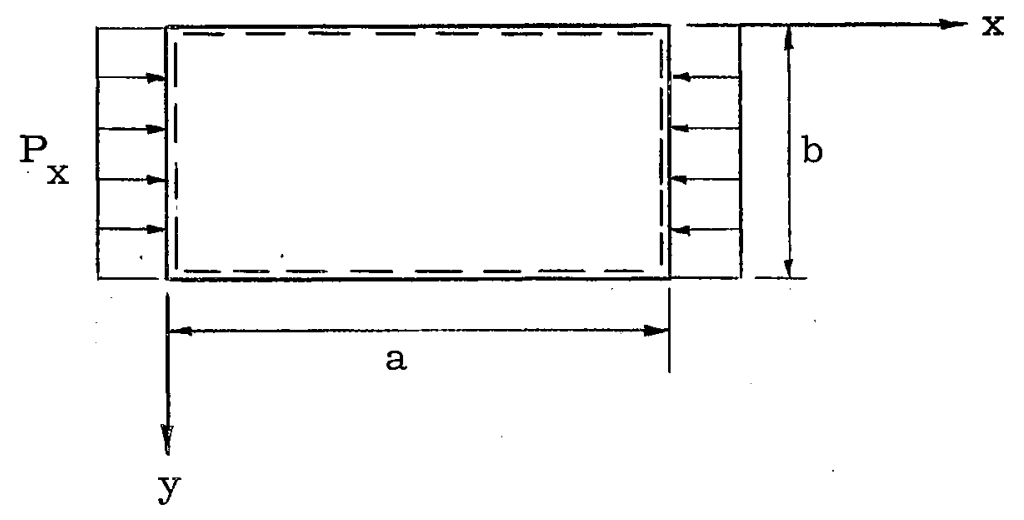

Figure 4 - A Simply Supported Rectangular Plate 
For this case

$$
\begin{gathered}
P=N_{y}=N_{x y}=0 \quad N_{x}=-P_{x} \\
R=-P_{x} w, x x
\end{gathered}
$$

And $G_{x}, G_{y}, D, \nu_{D}, F_{D}$ are constants as defined by equation (48)。

The governing equations are

$$
\begin{aligned}
& \mathrm{D} \alpha, \mathrm{xx}+\mathrm{F}_{\mathrm{D}}{ }_{,}, \mathrm{yy} \\
& +\left(\mathrm{D} \nu_{\mathrm{D}}+\mathrm{F}_{\mathrm{D}}\right) \beta, \mathrm{xy}-\mathrm{G}_{\mathrm{x}}(\alpha+\mathrm{w}, \mathrm{x})=0 \\
& \mathrm{~F}_{\mathrm{D}}{ }_{, \mathrm{xx}}+\mathrm{D} \beta, \mathrm{yy}+\left(\mathrm{D} \nu_{\mathrm{D}}+\mathrm{F}_{\mathrm{D}}\right) \alpha, \mathrm{xy}-\mathrm{G}_{\mathrm{y}}(\beta+\mathrm{w}, \mathrm{y})=0 \\
& \mathrm{D}\left(\alpha_{, \mathrm{xxx}}+\beta_{, \mathrm{yyy}}\right)+\left(\mathrm{D} \nu_{\mathrm{D}}+2 \mathrm{~F}_{\mathrm{D}}\right)\left(\alpha, \mathrm{xyy}+{ }_{, \mathrm{xxy}}\right)+\mathrm{R}=0
\end{aligned}
$$

Assume solution of the series form:

$$
\begin{aligned}
& w=\sum_{m} \sum_{n} w_{m n} \sin \frac{m \pi x}{a} \sin \frac{n \pi y}{b} \\
& \alpha=\sum_{m} \sum_{n} A_{m n} \cos \frac{m \pi x}{a} \sin \frac{n \pi y}{b} \\
& \beta=\sum_{m} \sum_{n} B_{m n} \sin \frac{m \pi x}{a} \cos \frac{n \pi y}{b}
\end{aligned}
$$

each term of which satisfies the boundary conditions:

$$
\text { at } \quad \begin{aligned}
x & =0, x=a \\
w & =0 \\
M_{x} & =D\left(\alpha, x+\nu_{D} \beta, y\right)=0 \\
\beta & =0
\end{aligned}
$$


at

$$
\begin{aligned}
& \mathrm{y}=0, \mathrm{y}=\mathrm{b} \\
& \mathrm{w}=0 \\
& \mathrm{M}_{\mathrm{y}}=\mathrm{D}\left(\beta, \mathrm{y}+\nu_{\mathrm{D}^{\alpha}, \mathrm{x}}\right)=0 \\
& \alpha=0
\end{aligned}
$$

Substitute equations (106), (107), and (108) into equations (103), (104), and (105):

$$
\begin{aligned}
& {\left[D\left(\frac{m \pi}{a}\right)^{2}+F_{D}\left(\frac{n \pi}{b}\right)^{2}+G_{x}\right] A_{m n}+\left(\frac{m \pi}{a}\right)\left(\frac{n \pi}{b}\right)\left(D \nu_{D}+F_{D}\right) B_{m n}} \\
& +\frac{\mathrm{m} \pi}{\mathrm{a}} \cdot \mathrm{G}_{\mathrm{x}} \mathrm{W}_{\mathrm{mn}}=0 \\
& \left(\frac{m \pi}{a}\right)\left(\frac{n \pi}{b}\right)\left(D \nu_{D}+F_{D}\right) A_{m n}+\left[D\left(\frac{n \pi}{b}\right)^{2}+F_{D}\left(\frac{m \pi}{a}\right)^{2}+G_{y}\right] B_{m n} \\
& +\frac{\mathrm{n} \pi}{\mathrm{b}} \mathrm{G}_{\mathrm{y}} \mathrm{W}_{\mathrm{mn}}=0 \\
& {\left[D\left(\frac{m \pi}{a}\right)^{3}+\left(D \nu_{D}+2 F_{D}\right)\left(\frac{m \pi}{a}\right)\left(\frac{n \pi}{b}\right)^{2}\right] A_{m n}} \\
& +\left[D\left(\frac{n \pi}{b}\right)^{3}+\left(D \nu_{D}+2 F D\right)\left(\frac{m \pi}{a}\right)^{2}\left(\frac{n \pi}{b}\right)\right] B_{m n} \\
& +\left(\frac{\mathrm{m} \pi}{\mathrm{a}}\right)^{2} \mathrm{P}_{\mathrm{x}} \mathrm{W}_{\mathrm{mn}}=0
\end{aligned}
$$

For critical load, the following determinant must vanish:

$$
\left|\begin{array}{lll}
D\left(\frac{m \pi}{a}\right)^{2}+F_{D}\left(\frac{n \pi}{b}\right)^{2}+G_{x} & \left(\frac{m \pi}{a}\right)\left(\frac{n \pi}{b}\right)\left(D \nu_{D}+F_{D}\right) & \frac{m \pi}{a} G_{x} \\
\left(\frac{m \pi}{a}\right)\left(\frac{n \pi}{b}\right)\left(D \nu_{D}+F_{D}\right) & D\left(\frac{n \pi}{b}\right)^{2}+F_{D}\left(\frac{m \pi}{a}\right)^{2}+G_{y} & \frac{n \pi}{b} G_{y} \\
D\left(\frac{m \pi}{a}\right)^{3}+\left(D \nu_{D}+2 F_{D}\right)\left(\frac{m \pi}{a}\right)\left(\frac{n \pi}{b}\right)^{2} & D\left(\frac{n \pi}{b}\right)^{3}+\left(D \nu_{D}+2 F_{D}\right)\left(\frac{m \pi}{a}\right)^{2}\left(\frac{n \pi}{b}\right) & \left(\frac{m \pi}{a}\right)^{2} P_{x}
\end{array}\right|=0
$$


For fundamental mode, set $\mathrm{m}=\mathrm{n}=1$ in equation (113) and solve for $\mathrm{P}_{\mathrm{x}}$.

\subsection{Example 2}

A rectangular multilayer sandwich plate simply supported along all edges is subjected to a uniform distributed compressive load of intensity $\mathrm{P}_{\mathrm{x}}$. Assume all facing membrane layers have the same Poisson's ratio. Determine the critical load.

$$
\begin{gathered}
P=N_{y}=N_{x y}=0 \quad N_{x}=-P_{x} \\
R=-P_{x}{ }^{w}, x x
\end{gathered}
$$

And $\mathrm{D}, \nu, \mathrm{K}_{\mathrm{x}}, \mathrm{K}_{\mathrm{y}}$ are constants which may be calculated from the respective defining equations.

The governing equation is

$$
\begin{aligned}
& {\left[1-K_{y} \frac{\partial^{2}}{\partial x^{2}}-K_{x} \frac{\partial^{2}}{\partial y^{2}}\right] \nabla^{4} w} \\
& +\left[1-\left(\frac{2 \mathrm{~K}}{1-\nu}+\mathrm{K}_{\mathrm{y}}\right)-\frac{\partial^{2}}{\partial \mathrm{x}^{2}}-\left(\mathrm{K}_{\mathrm{x}}+\frac{2 \mathrm{~K}}{1-\nu}\right) \frac{\partial^{2}}{\partial \mathrm{y}^{2}}\right. \\
& \left.+\frac{2 \mathrm{~K}_{\mathrm{x}} \mathrm{K} y}{1-\mathrm{v}} \nabla^{4}\right]^{\mathrm{N}_{\mathrm{x}} \mathrm{w}, \mathrm{xx}}=0
\end{aligned}
$$

Assume solution of the series form:

$$
\mathrm{w}=\sum_{\mathrm{m}} \sum_{\mathrm{n}} \mathrm{w}_{\mathrm{mn}} \sin \frac{\mathrm{m} \pi \mathrm{x}}{\mathrm{a}} \sin \frac{\mathrm{n} \pi \mathrm{x}}{\mathrm{b}}
$$




$$
\begin{aligned}
& \alpha=\sum_{\mathrm{m}} \sum_{\mathrm{n}} \mathrm{A}_{\mathrm{mn}} \cos \frac{\mathrm{m} \pi \mathrm{x}}{\mathrm{a}} \sin \frac{\mathrm{n} \pi \mathrm{x}}{\mathrm{b}} \\
& \beta=\sum_{\mathrm{m}} \sum_{\mathrm{n}} \mathrm{B}_{\mathrm{mn}} \sin \frac{\mathrm{m} \pi \mathrm{x}}{\mathrm{a}} \cos \frac{\mathrm{n} \pi \mathrm{x}}{\mathrm{b}}
\end{aligned}
$$

each term of which satisfies the boundary conditions of equation (107). Substitute equations (115), (116), and (117) into equation (114), then

$$
\begin{aligned}
& {\left[1+K_{x}\left(\frac{n \pi}{b}\right)^{2}+K_{y}\left(\frac{m \pi}{a}\right)^{2}\right]\left[\left(\frac{m \pi}{a}\right)^{2}+\left(\frac{n \pi}{b}\right)^{2}\right]^{2} W_{m n}} \\
& =\left\{\left[1+K_{x}\left(\frac{n \pi}{b}\right)^{2}+K_{y}\left(\frac{m \pi}{a}\right)^{2}\right]\right. \\
& +\frac{2}{1-\nu}\left[K_{x} K_{y}\left(\frac{m^{2} \pi^{2}}{a^{2}}+\frac{n^{2} \pi^{2}}{b^{2}}\right)^{2}+K_{x}\left(\frac{m \pi}{a}\right)^{2}\right. \\
& \left.\left.+K_{y}\left(\frac{n \pi}{b}\right)^{2}\right]\right\} \frac{P_{x}}{D}\left(\frac{m \pi}{a}\right)^{2} W_{m n}
\end{aligned}
$$

Hence the critical load is

$$
P_{x}=\left(\frac{a}{m \pi}\right)^{2} \cdot \frac{P A}{P B+P C}
$$

where

$$
P A=D\left[1+K_{x}\left(\frac{n \pi^{2}}{b}\right)^{2}+K_{y}\left(\frac{m \pi}{a}\right)^{2}\right]\left[\left(\frac{m \pi}{a}\right)^{2}+\left(\frac{n \pi}{b}\right)^{2}\right]^{2}
$$




$$
\begin{aligned}
& \mathrm{PB}=1+\mathrm{K}_{\mathrm{x}}\left(\frac{\mathrm{n} \pi}{\mathrm{b}}\right)^{2}+\mathrm{K}_{\mathrm{y}}\left(\frac{\mathrm{m} \pi}{\mathrm{a}}\right)^{2} \\
& \mathrm{PC}=\frac{2}{1-\nu}\left\{\mathrm{K}_{\mathrm{x}} \mathrm{K}_{\mathrm{y}}\left[\left(\frac{\mathrm{m} \pi}{\mathrm{a}}\right)^{2}+\left(\frac{\mathrm{n \pi}}{\mathrm{b}}\right)^{2}\right]^{2}+\mathrm{K}_{\mathrm{x}}\left(\frac{\mathrm{m \pi}}{\mathrm{a}}\right)^{2}+\mathrm{K}_{\mathrm{y}}\left(\frac{\mathrm{n \pi})^{2}}{\mathrm{~b}}\right)^{2}\right.
\end{aligned}
$$

For fundamental mode, set $m=n=1$ in equation (118) and calculate $\mathrm{P}_{\mathrm{x}}$ 。 


\section{CHAPTER VI}

\section{SUMMARY AND CONCLUSIONS}

\section{1 Summary and Conclusions}

A theory defining the stability of multilayer sandwich plates has been developed in this thesis. The development of the theory consists mainly of the formulation of an auxiliary functional, application of the minimizing principle and the elimination process. The problem is formulated in a complete Lagrange form with stresses taken as independent variables and stress resultants as dependent variables. The elegance of the Lagrange formulation is realized and illustrated in this study.

The successful selection of a reference surface, the weighted neutral surface, leads to the governing equations for the stability of multilayer sandwich plates subjected to assumptions less restricted than most previous works. This weighted neutral surface has not appeared previously in any available literature.

A set of five nonlinear differential equations governing the stability of multilayer sandwich plates is obtained. When specialization for equal Poisson's ratios is made, the governing equation is a sixth order partial differential equation. For isotropic core layers, the governing differential equation becomes a fourth order equation.

Though the mathematical model used is a five-layer sandwich plate, the approach is perfectly general. For sandwich plates composed 
of more than five layers, the governing equations are also valid, provided that the indices of property coefficients are adjusted accordingly.

\subsection{Comparison of Results}

Equation (96) is the governing differential equation for the stability of multilayer sandwich plates with equal Poisson's ratios for all facing membrane layers and orthotropic core layers. For pure bending, replace $R$ by $P$, then equation (98) reduces to

$$
\begin{aligned}
& {\left[1-\mathrm{K}_{\mathrm{y}} \frac{\partial^{2}}{\partial \mathrm{x}^{2}}-\mathrm{K}_{\mathrm{x}} \frac{\partial^{2}}{\partial \mathrm{y}^{2}}\right] \nabla^{4} \mathrm{w}} \\
& \quad=\left[1-\left(\frac{2 \mathrm{~K}}{1-\nu}+\mathrm{K}_{\mathrm{y}}\right) \frac{\partial^{2}}{\partial \mathrm{x}^{2}}-\left(\mathrm{K}_{\mathrm{x}}+\frac{2 \mathrm{~K}_{\mathrm{y}}}{1-\nu}\right) \frac{\partial^{2}}{\partial \mathrm{y}^{2}}+\frac{2 \mathrm{~K}_{\mathrm{x}} \mathrm{K}}{1-\nu} \nabla^{4}\right] \frac{\mathrm{P}}{\mathrm{D}}
\end{aligned}
$$

which is the same as given by $B . D_{0}$ Liaw $^{(4)}$.

For the bending of a three-layer sandwich plate with identical facing layers and an orthotropic core, the equation given by S. Cheng ${ }^{(3)}$ is a special case of equation (119).

For the bucking of three-layer sandwich plates with isotropic core, the equation developed by E. Reissner ${ }^{(6)}$ is a special case of equation (102). 


\section{A SELECTED BIBLIOGRA PHY}

\section{LITERATURE SURVEY}

1. Habip, L. M. "A Survey of Modern Developments in the Analysis of Sandwich Structures." Appl. Mech. Review, Vol. 18, No. 2, 1965.

2. Stiter, G.E., R. J. Nikolai and A.P. Boresi, "Elastic Plates: Annoted Bibliography 1930-1962." Engr. Experiment Station Technical Report No. 10, University of Illinois, Urbana, IIlinois, 1964, pp. 91-97, pp. 159-167.

\section{SPECIAL REFERENCES}

3. Cheng, S. "On the Theory of Bending of Sandwich Plates." Proc. Fourth U.S. Nat. Cong. Appl. Mech., 1962, pp. 511-518.

4. Liaw, B.D. "Theory of Bending of Multilayer Sandwich Plates." $\mathrm{Ph}$. D. Thesis, Oklahoma State University, Stillwater, Oklahoma, 1965.

5. Reissner, E. "On Bending of Elastic Plates." Quar. Appl. Math., Vol. 5, 1947, pp.55-68.

6. Reissner, E。 "Finite Deflections of Sandwich Plates。" Jour. Aero.Sci., Vol.15, 1948, pp. 435-440.

\section{GENERAL REFERENCES: ARTICLES}

7. Chang, C.C. and I. K. Ebicoglu. "Elastic Instability of Rectangular Sandwich Panel of Orthotropic Core with Different Face Thickness and Materials." Jour. Appl. Mech., Trans. ASME, Vol. 82, 1960, pp. 474-480。

8. Eringen, A.C. "Bending and Buckling of Rectangular Sandwich Plates." Proc, First U.S. Nat. Cong. Appl。 Mech., 1951 , pp. 381-390.

9. Gerard, G。 "Linear Bending Theory of Isotropic Sandwich Plates by Order-of-Magnitude Analysis." Jour. Appl. Mech。, Trans. ASME, Vol。74, 1952, pp. 13-15. 
10. Hoff, N.J. "Bending and Buckling of Rectangular Sandwich Plates." NACA Tech. Note 2225, 1950.

11. Libove, C. and S.B. Batdorf. "A General Small-Deflection Theory for Flat Sandwich Plates." NACA Tech. Note 1526, 1948 .

12. Reissner, E. "Small Bending and Stretching of Sandwich Type Shells." NACA Tech. Note 1832, 1949.

13. Wang, C.T. "Principle and Application of Complementary Energy for Thin Homogeneous and Sandwich Plates and Shells with Finite Deflections." NACA Tech. Note 2620, 1952.

14. Yu, Y.Y. "A New Theory of Sandwich Plates - One Dimensional Case." Jour. Appl. Mech., Trans. ASME, Vol.81, 1959, pp. $415-\overline{421}$.

\section{GENERAL REFERENCE: BOOKS}

15. Bleich, F。 Buckling Strength of Metal Structures. McGrawHill Book Co., Inc, New York, 1952, pp. 302-357.

16. Cox, C.L。 The Buckling of Plates and Shells. The MacMillian Co., New York, 1963, pp. 1-46.

17. Fung, Y.C. Foundation of Solid Mechanics. Prentice-Hall, Inc., Englewood, New Jersey, 1956, pp. 293-300.

18. Langhaar, H. L. Energy Methods in Applied Mechanics. John Wiley and Sons, Inc., New York, 1962, pp. 91-92, pp. 119-133.

19. Mansfield, E.H. The Bending and Stretching of Plates. The MacMilliam Co., New York, 1964, pp. 1-34.

20. Sokolnikoff, I.S. Mathematical Theory of Elasticity. 2nd Ed. McGraw-Hill Book Co., Inc., New York, 1956, pp.387-390.

21. Timoshenko, S.F. and J. M. Gere. Theory of Elastic Stability. 2nd Ed. McGraw-Hill Book Co., Inc., New York, 1961, pp. 348-439.

22. Tuma, J. J., K. S. Havner and S. E. French, Jr。 "Analysis of Flat Plates by the Algebraic Carry-Over Method. Engr. Res. Bull., Oklahoma State University, Stillwater, Okla., Vol. 1, 1960, Chapter 1 and Chapter 2.

23. Wang, C.T. Applied Elasticity. McGraw-Hill Book Co。, Inc. New York, 1953, pp.148-151. 


\author{
VITA \\ Julius Pan Wong \\ Candidate for the Degree of \\ Doctor of Philosophy
}

Thesis: STABILITY OF MULTILAYER SANDWICH PLATES

Major Field: Engineering

Biographical:

Personal Data: Born May 8, 1937, in Shanghai, China, the son of $\mathrm{K}$. S. and $\mathrm{P}$. L。 Wong.

Education: Graduated from Bethel High School, Hong Kong in June, 1956. Received the degree of Diploma in Civil Engineering from Hong Kong Baptist College, Hong Kong, June, 1960. Received the Degree of Master of Science in Civil Engineering from Louisiana Polytechnic Institute, Ruston, Louisiana, May, 1962. Completed the requirements for the degree of Doctor of Philosophy May, 1966.

Professional Experience: Surveying work for $T$. L o James Co., Ruston, Louisiana, summer, 1961. Graduate Assistant 2. Oklahoma Stete University,:1962-1966. Associate member of $\mathrm{ASCE}$ and member of $\mathrm{ACI}$. 